\title{
Student to Student and Families too
} Beyond the campus: IU Connects

KAYLA NUNNALLY

\section{PROGRAM OVERVIEW}

Indiana University is connecting with students and families across the state to support equitable access to quality education, educational resources, and social-emotional support. In 2016, the IUPUI Office of Community Engagement was awarded a grant funded by Serve Indiana to provide free tutoring, mentoring, and college/career readiness workshops to students in grades 6-12. Services are delivered in-person, via online conferencing, and by telephone to ensure all students and their parent/caregivers have equitable access. In total, seven IU campuses (East, Southeast, Northwest, South Bend, Kokomo, Bloomington and IUPUI) serve over 2,200 students from rural, urban and suburban communities during the school year and summer. Each of the campuses provide face-to-face programming in their local community at schools, community centers, libraries or on the college campus. IUPUI serves as the hub for online tutoring and mentoring.

\section{COllaborative LEADERSHIP}

A collaborative leadership approach is followed, in which responsibility is shared to achieve equitable outcomes for school communities. Dr. Khaula Murtadha, Associate Vice Chancellor for the Office of Community Engagement; Kayla Nunnally, Program Manager; and Nicole Oglesby, Director of P-20 Alliances, lead IUPUI programming. Dr. Silvia Garcia, also from the IUPUI campus, leads evaluation of the program. Dr. Chris Chalker coordinates and supervises on-campus sessions, as well as facilitates caregiver workshops at IUPUI. At IU East Ann Tobin, Campus/Community Service-Learning Liaison, leads the program. Dr. Gloria Murray, Interim Director of the Office of 


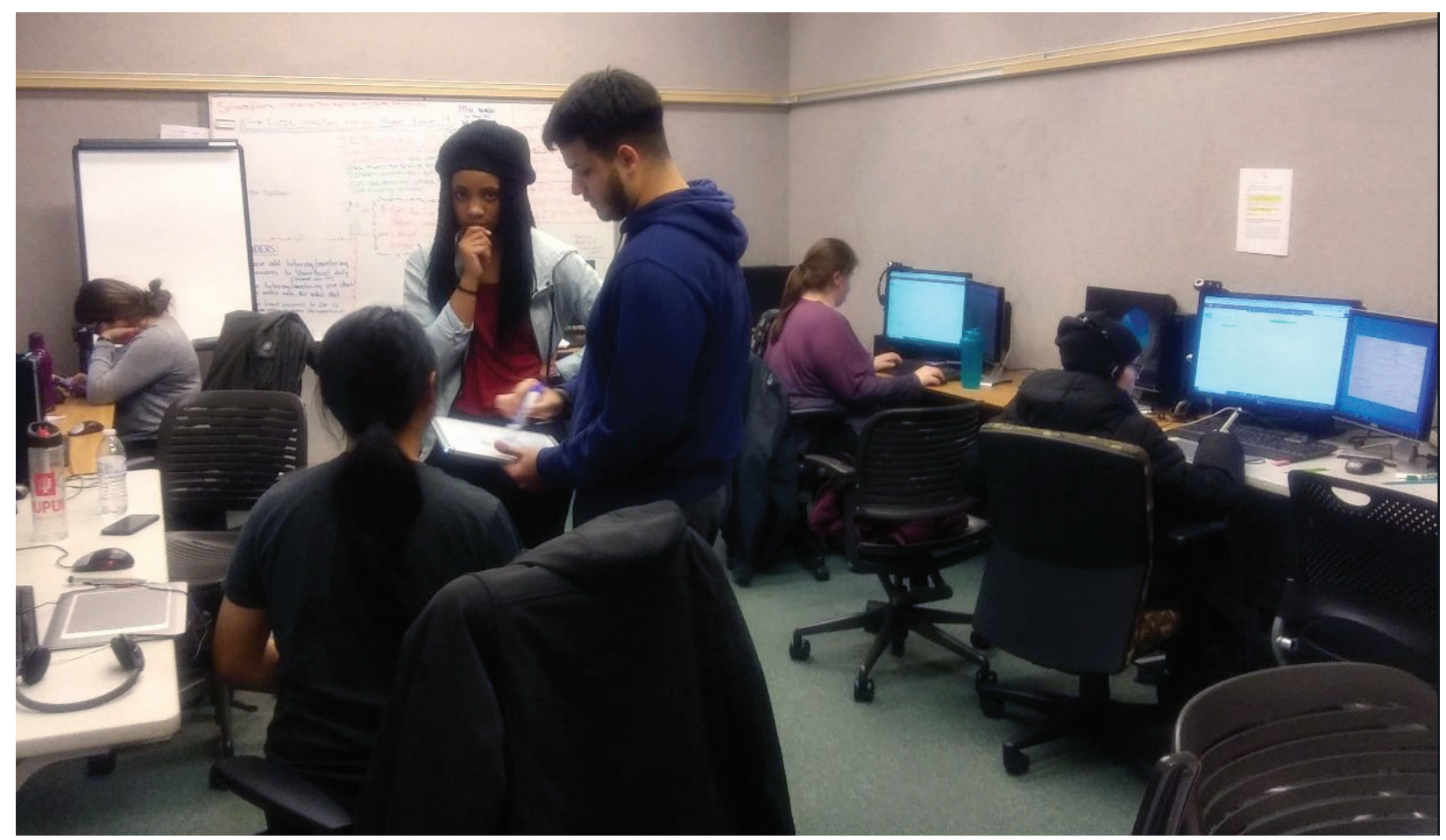

Indiana Kids mentors work during a recent online tutoring hours session. Photo credit: Chris Chalker, IUPUI

Service Learning and Community Engagement, and Emily Seay, Program Manager, move the program forward on the IU Southeast campus. Ginny Heidemann, Director of Academic Centers for Excellence serves as the program director for the IU South Bend campus. Sophie Haywood, Associate Director of P16 Research and Collaboration, oversees programming at IU Bloomington as does James Wallace, Director of the Office of Diversity, Equity and Multicultural Affairs at IU Northwest. The IU Kokomo campus is led by Makenzie Damon, Student Outreach Coordinator of Kelley Student Center and Tracy Springer, Director of Career and Accessibility Center. On each campus, IU college students from various backgrounds and academic disciplines serve as tutors and mentors. They also share leadership through workshop planning and facilitating, as well as supporting program evaluation.

\section{STUDENT TO STUDENT}

Since 2016, over 200 IU students have served in the program. The program works to ensure that they are developing as civic-minded scholars, beyond their time with the program. Throughout their service, they attend professional development sessions with topics such as supporting bilingual students, developing cultural competency, racism and implicit bias, as well as how adverse childhood experiences and trauma affect their work with students. Tutors and mentors also are able to request professional development topics based on what they are experiencing in their dayto-day work. Some of the current tutors/mentors were once enrolled in the program as high school students. As they expressed, because of their participation in the program, not only did they decide to attend IU, but they also wanted to give back to their community and serve.

IU Indiana Kids tutors/mentors speak to the impact on their personal and professional lives. "Being part of the Indiana Kids team has been a really rewarding opportunity. Growing up, I faced many struggles academically, so I am happy to be able to support students who are 
facing the same challenges I once faced," said Jose Maya-Rodriguez, a junior mechanical engineering major in the School of Engineering and Technology at IUPUI. He added, "This program gives me the motivation to keep learning so that I can share my knowledge with our students and to teach them that they are powerful beyond measure. Creating relationships and becoming a role model for the students we work with could make a huge difference in students' lives as we give them the tools to learn, grow and become a better version of themselves." Andrea Ruvalcaba, a junior in the School of Social Work at IUPUI, attributes her desire to serve as a tutor and mentor to her experience as a first-generation scholar. "This program has allowed me to be a resource and support system for children in the Indianapolis area." A tutor/mentor from the South Bend campus shared, "I most value the bonds that I was able to create with the students I helped. Watching that trust they had with me allowed them to feel free to try, fail, and succeed with difficult subjects."

Six through twelfth grade students in the program are able to attend as many tutoring, mentoring and college/career readiness sessions as they would like. They frequently mention that the program not only makes them feel more confident in school, but also makes learning fun. One student said, "Every mentor and tutor that I have worked with has showed me I can be me, and I don't have to get good grades on tests to prove to teachers that I work hard. I can continue to do what I do. They have helped me understand that I don't need to be afraid."

\section{FAMILY ENGAGEMENT}

Family engagement is promoted through resource dissemination and college/career readiness workshops. Workshops are tailored to be relevant and meaningful for families, addressing their expressed needs and interests. Some of the most common requested workshops include college

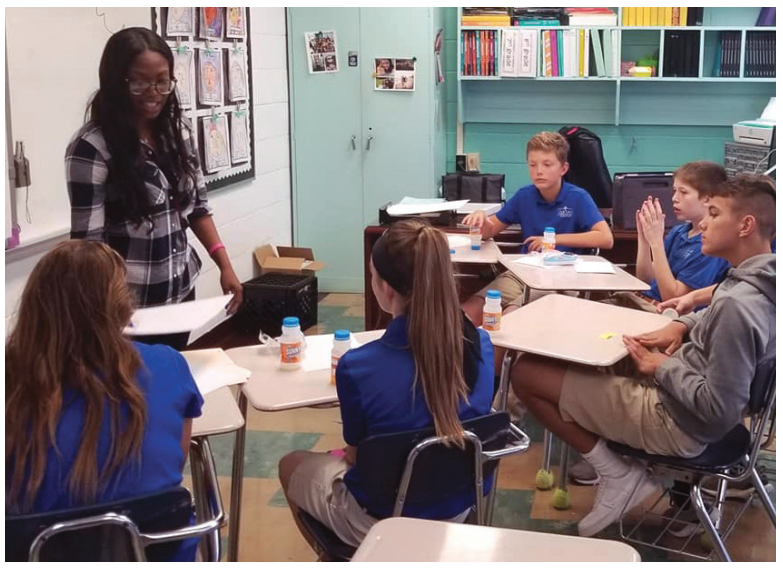

An Indiana Kids mentor talks to students during a school visit. Photo credit: IU Southeast Indiana Kids

financial awareness and college/career options. In the last year, the program has offered over 50 workshops for caregivers and students. For example, the IUPUI campus provides college and career readiness workshops with parents/caregivers one-on-one or in small groups while their middle or high school students receive tutoring and mentoring support. The IU Southeast campus focuses primarily on mentoring and workshops with schools and local nonprofits, including foster care providers and programs that support families of incarcerated individuals.

Parents/caregivers consistently express the positive impact of the program. One said, "The program is free. This is such a benefit and relief for parents. The workshops are an added bonus and help my child understand the importance of being college and career ready after high school." Another reported that her 10th grade student had never had an A+ on a test until being tutored through the program. A third parent/caregiver shared that her daughter is now eligible for athletic scholarships because of her grade improvement.

The connection between IU, families, and students helps to bridge the gap between school and home, providing equitable opportunities to educational resources and social-emotional support as students prepare for their futures. 


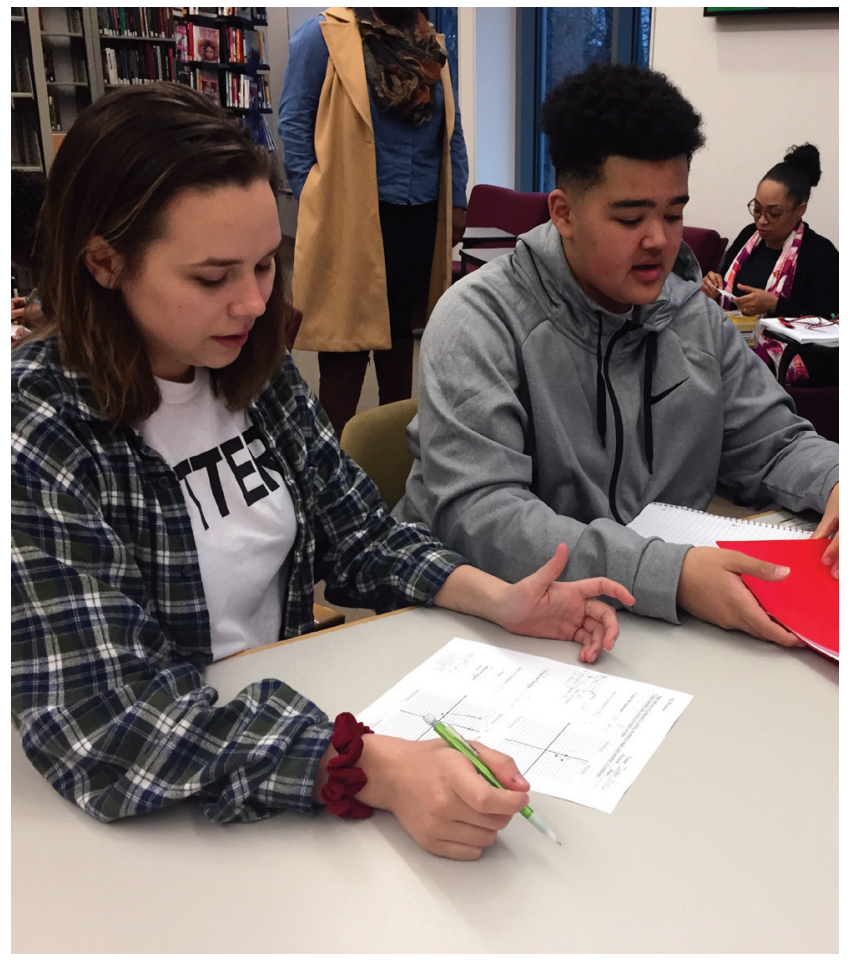

An Indiana Kids mentor and a student work together. Photo credit: IU Southeast Indiana Kids

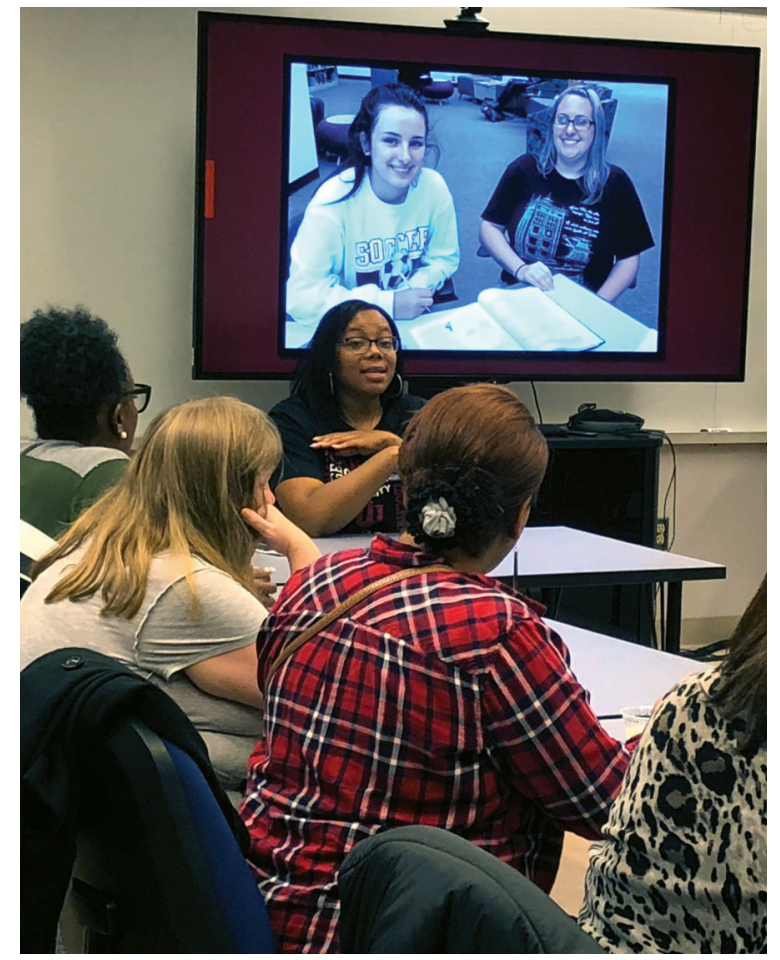

Parents are also invited to attend Indiana Kids workshops. Photo credit: Teresa Francis, IUPUI

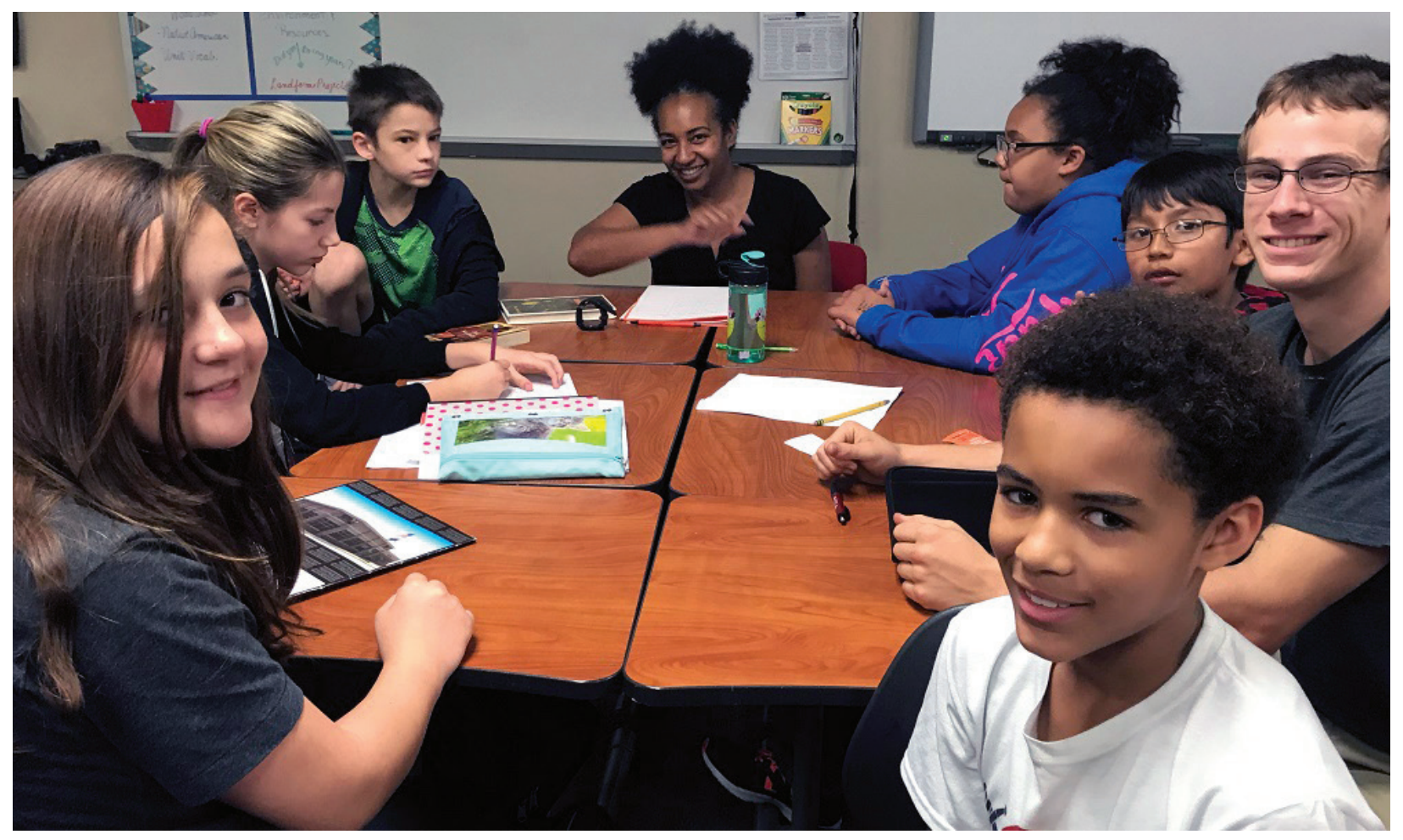

Students meet with Indiana Kids mentors at an event . Photo credit: IU East Indiana Kids 